\title{
Inhibition of the startle reflex in the rat by prior tactile stimulation
}

\author{
LINDA A. PINCKNEY \\ University of Rochester, Rochester New York 14627
}

\begin{abstract}
In Experiment 1, three groups of rats received a tactile prepulse $0.5,1$, or $2 \mathrm{~mA}$ electric shock (to feet) $.25, .5,1,5,10$, or $20 \mathrm{sec}$ prior to an acoustic startle stimulus. The startle response was maximally inhibited at the .25 -sec interval and gradually recovered thereafter. Inhibition was larger with the intense stimuli, and for the .5-mA stimulus occurred reliably only in animals which responded to the prestimulus. In Experiment 2, the intensity of the prepulse was varied within subjects at intervals of $.5,1$, and $2 \mathrm{sec}$. Inhibition was directly related to prestimulus intensity and was greatest at .5 sec. In Experiment 3, an EMG measure of startle reactivity allowed the use of shorter intervals. The maximal inhibitory interval between the prestimulus and startle stimulus was $40 \mathrm{msec}$ compared with either a shorter $10-\mathrm{msec}$ or a longer 250-msec separation.
\end{abstract}

The present series of experiments was designed to map out the temporal and intensity functions of the inhibitory effects of a tactile stimulus (produced by a brief electric shock) on an acoustic startle reaction in the rat. Amplitude and latency changes produced by single brief shocks were assessed as well as the more long-term aftereffects resulting from series of pairs of tactile and acoustic stimuli of various intensities.

Investigations of changes in reflex behavior following and during various diverse stimuli have been made intermittently since the late $1800 \mathrm{~s}$, but the greatest amount of knowledge about reflex inhibition and facilitation has accumulated within the last 10 years. It has been established that brief visual and auditory stimuli presented at appropriate intervals prior to the auditory startle reflex (Buckland, Buckland, Jamieson, \& Ison, 1969; Hoffman \& Searle, 1965), the reflex response to footshock (Ash, Parisi, \& Ison, Note 1), the human eyeblink response to airpuffs (Krauter, Leonard, \& Ison, 1973) and noise (Graham, 1975), the nictitating membrane reflex in rabbits (Ison \& Leonard, 1971), and the visual startle reaction in pigeons (Stitt, Hoffman, Marsh, \& Schwartz, 1976) produce reflex inhibition. In these experiments, inhibition has been found to be a function of the strength of the prestimulus $\left(S_{1}\right)$ and the interval between $S_{1}$ and the eliciting stimulus $\left(S_{2}\right)$. Up to the time of the present experiments, only auditory and visual prestimuli had been systematically investigated, although Brown,

This research was supported by a Public Health Service research grant, 1R01 NS-12443, and by a National Science Foundation research grant, GB-14814, to James $R$. Ison. Requests for reprints should be sent to Linda A. Pinckney, now at Department of Psychology, Nazareth College of Rochester, Rochester, New York 14610.
Meryman, and Marzocco (1956) have shown that relatively prolonged and intense exposure to electric shock (3-5 sec long) inhibited rats' startle behavior elicited 1-3 sec following shock termination. The studies reported here were intended primarily to extend the generality of the prior findings. One special contribution of the present research was that the tactile stimulus elicited a response of approximately the same topography as the acoustic startle, i.e., a sudden flinch. This enabled an examination of the relationship between the response-eliciting properties of a preliminary stimulus and its reflex inhibiting potency, when the prestimulus and eliciting stimulus derive from different modalities.

\section{EXPERIMENT 1}

In this experiment, a wide range of intervals between the shock prepulse and the startle stimulus were used. The shortest ISI was $250 \mathrm{msec}$, which was the shortest interval at which the response to $S_{1}$ and the response to $S_{2}$ could be distinguished; the longest ISI was $20 \mathrm{sec}$. The intensity of the shock was varied with the expectation that stronger shock would produce greater inhibition as has been found with light and tone prepulses (Hoffman \& Wible, 1970; Ison \& Hammond, 1971). The strength of the auditory startle stimulus was also varied.

In addition to the inhibitory effect of the brief shock prepulses, a cumulative effect of shock throughout the experimental session might provide a general increase in sensitization or activation, yielding a shift in control startle responding as the session progressed. This possibility was tested by comparing a series of control trials given before with a second series given after the shock trials. 


\section{Method}

Subjects. The subjects were 44 male albino rats, 120 to 150 days old, obtained from Carworth, New City, New York. Eighteen of these rats were previously run in a food-reinforced runway experiment 1 month prior to the present experiment. Rats were maintained on ad-lib food and water and housed in group cages prior to and during the experiment.

Apparatus. The apparatus for the measurement of the startle reflex was similar to that described by Ison and Hammond (1971). It consisted of a perforated Plexiglas compartment $(8 \times 3.5 \times 2.5 \mathrm{in}$. high; $20.3 \times 8.9 \times 6.4 \mathrm{~cm})$, set on springs within an aluminum superstructure, and housed within an IAC audiometric room. A signal from an accelerometer, which was attached to one side of the Plexiglas chamber, was fed into a Beckman Dynograph (Type 9856), and recorded as the extent of pen deflection (millimeters). The startle stimulus was a 9,000-cps tone of $25 \mathrm{msec}$ duration, including a 5 -msec rise and decay time, which was delivered, following amplification, through a Lansing high-frequency tweeter. A 4-in. cone speaker directed at the cage provided a 70-dB (re: 0002 dynes $/ \mathrm{cm}^{2}$ ) white noise background stimulus. The startle stimulus duration and interstimulus intervals were produced by Hunter timers (Model 111B).

The floor of the startle chamber consisted of two aluminum plates separated by a space of $1 / 2$ in. Current was delivered to these plates by a Grass stimulator (Model SD5), in combination with a constant current unit (Model CCU1). The duration of the shock was controlled by the stimulator.

Procedure. Three minutes after being placed in the startle chamber, each rat received a pretest, during which five startle pulses were delivered at an average 2 -min intertrial interval (ITI). Two minutes after the last pretest trial, the experimental session began. Four groups of subjects received 0 , .5-, 1-, or 2-mA shock as a $1-\mathrm{msec}$ pulse prior to the startle pulse, with each subject receiving five trials at each of six intervals between the shock prepulse and the startle stimulus- $.25, .5,1,5,10$, and $20 \mathrm{sec}$-as well as five control trials on which the startle stimulus was presented alone. Intervals were presented in a random order with a mean 2 -min ITI, varying from 90 to $150 \mathrm{sec}$. Following the last shock trial, five posttest control trials were delivered at an average 2 -min ITI. Twelve subjects were run in each of the three shock intensity groups $(.5,1,2 \mathrm{~mA})$, six rats receiving a high $(120 \mathrm{~dB})$ and six a low $(100 \mathrm{~dB})$ startle stimulus. The 0-shock-intensity group contained eight rats, four at each startle intensity. This group served as an additional control and received only startle pulses without preliminary shock. (Detailed description of apparatus and procedure are presented in Pinckney, 1970.)

\section{Results and Discussion}

The mean startle amplitude for each prepulse intensity over the six ISIs (100- and 120-dB startle intensities combined) are shown in Figure 1. The greatest amount of inhibition occurred with the shortest ISIs, and the 1- and 2-mA prepulses resulted in greater inhibition than the .5-mA prepulse. An analysis of these data showed significant effects of ISI $(F=19.15, \mathrm{df}=6 / 180, \mathrm{p}<.001)$ and prepulse intensity $(F=4.01, \mathrm{df}=2 / 30, \mathrm{p}<.05)$ as well as a significant ISI by Prepulse Intensity interaction $(F=2.06, \mathrm{df}=12 / 180, \mathrm{p}<.05)$. There was no main effect of startle stimulus intensity or its interaction with other variables. Separate analyses indicated that the four groups differed at the shortest ISI but not in their respective control levels, and that at the shortest ISI, the 1- and 2-mA groups differed from the $.5-\mathrm{mA}$ group $(\mathrm{t}=2.44, \mathrm{df}=22$,

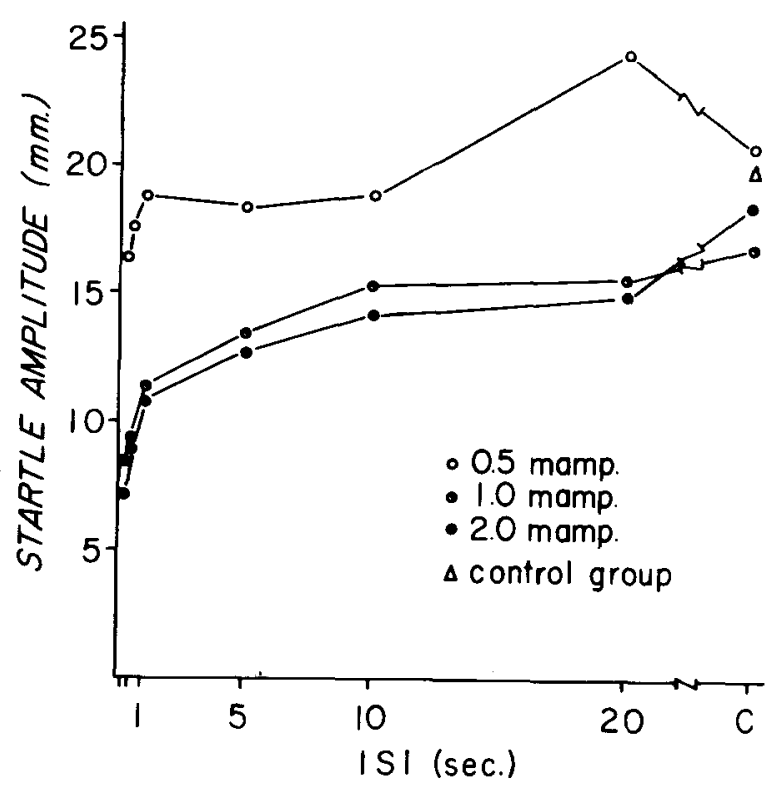

Figure 1. Mean startle amplitudes for each shock prepulse intensity group (control, .5, 1, $2 \mathrm{~mA}$ ) at each ISI $(.25, .5,1,5$, $10,20 \mathrm{sec}$ ) and control condition.

$\mathrm{p}<.05$, and $\mathrm{t}=3.07$, df $=22, \mathrm{p}<.01$, respectively) and the control group $(t=3.42$, and 4.94 , respectively, $\mathrm{df}=18, \mathrm{p}<.01$ ) but not from each other.

Further analysis within groups using each group's own control level revealed that the startle amplitude with a 2-mA prepulse was significantly lower than its control level with a 20 -sec ISI $(t=3.05$, $\mathrm{df}=11, \mathrm{p}<.02$ ) and all shorter ISIs, while inhibition of the startle response relative to its control level in the 1-mA group was significant only with a 5-sec ISI $(t=2.43$, df $=11, p<.05)$ and all shorter ISIs. This suggests that inhibition lasted longer with a 2-mA prepulse than with a $1-\mathrm{mA}$ prepulse, although the absolute amount of inhibition with the shortest ISI did not differ with the two prepulse intensities.

Overall, the .5-mA group showed no significant differences between response amplitude at any ISI and its control level, although the general shape of the function is similar to the other groups and may be indicative of the presence of a weak inhibitory effect. Inspection of individual performance in this group revealed an obvious relationship between the average response to $S_{1}$ and average inhibition of the response to $S_{2}$ at short ISIs, so that animals responding little or none to $S_{1}$ did not exhibit any inhibition of response to $S_{2}$.

Four of the 12 rats in this group gave little or no response to $S_{1}(M=.66)$ and also did not inhibit their response to $S_{2}(M=-.33 .34 \%)$, suggesting that perhaps the shock was below threshold for both inhibition and motor elicitation for these animals. The other eight rats responded to $S_{1}(M=2.99)$ 

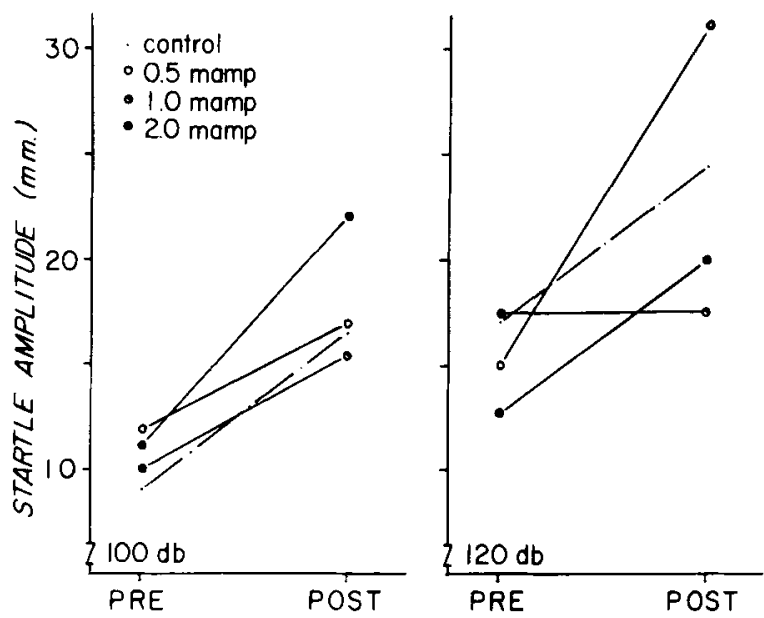

Figure 2. Mean startle amplitudes for the pretest (PRE) and posttest (POST) for each shock intensity (control, .5, 1, $2 \mathrm{~mA}$ ), the four 100-dB startle stimulus intensity groups shown on the left and the four 120-dB groups shown on the right.

and also inhibited their response to $S_{2}(M=41.63 \%$; $\mathrm{t}=4.10$, df $=7, \mathrm{p}<.01)$. There was no consistent relationship between the response to $S_{1}$ and the amount of inhibition on individual trials in this group or in the other groups.

The mean startle amplitudes during the pretest and the posttest are shown in Figure 2 for both the 100 and $120-\mathrm{dB}$ startle pulse intensities. The most salient characteristic of these data is the general increase in response amplitude from pretest to posttest, an increase which occurred in the experimental and control groups alike. An analysis of these data showed only a significant increase in startle from pre- to posttest $(F=20.32, \mathrm{df}=1 / 40, p<.01)$ and a significant effect of startle intensity $(F=6.87$, $\mathrm{df}=1 / 40, \mathrm{p}<.05)$. There was no interaction between pre- and posttest and the presence or absence of shock, its intensity, or the intensity of the startle stimulus. Recent data reported by Davis (1974) reveals that prolonged experience in the white noise background is sufficient to produce a substantial increase in the startle amplitude in rats, and this exposure alone may have been responsible for the effect in the present experiment. This seems especially likely given that the increase in responding found here was not dependent on the presence or intensity of $S_{1}$ or on the intensity of $S_{2}$.

\section{EXPERIMENT 2}

In the preceding experiment, the absolute amounts of inhibition produced by the 1 - and $2-\mathrm{mA}$ prepulses were not reliably different. However, the between-subject design used in that experiment is not the most precise and sensitive measure of stimulus intensity effects. It was used primarily to see whether different shock intensities might provide different levels of sensitization, which might have differentially affected control levels. The present experiment used a design in which both $\mathrm{S}_{1}$ intensity and ISI were imposed on the same subject, allowing a more sensitive examination of the intensity variable.

\section{Method}

Subjects and Apparatus. The subjects were naive rats of the same age and population as Experiment 1, and the same apparatus was used.

Procedure. The procedure was similar to that used in the first experiment, the major difference being that both shock prepulse intensity and ISI were within-subject variables. Each of eight subjects received five trials with $0-, .5-, 1-$, or $2-\mathrm{mA}$ shock as $S_{1}$ at each of three ISIs- $-5,5$, and $20 \mathrm{sec}$. Five pretest trials were run mainly to settle the rats down. The posttest was omitted. All trials were run with a 120-dB startle stimulus and a variable 2 -min ITI $(90-150 \mathrm{sec})$. All other parameters were identical to the preceding experiment.

\section{Results and Discussion}

The mean startle amplitudes are shown in Figure 3. The overall analysis of these data showed a significant effect of ISI $(F=5.71$, df $=3 / 21, p<.01)$ and an ISI by. Prepulse Intensity interaction $(\mathbf{F}=3.29$, $\mathrm{df}=6 / 42, \mathrm{p}<.01)$. Further analyses revealed that, with the .5-sec ISI, the inhibition produced by the 1-mA prepulse was significantly greater than that produced by the $.5-\mathrm{mA}$ prepulse $(\mathrm{t}=2.98$, df $=7$, $\mathrm{p}<.025$ ) and significantly less than that produced by the $2-\mathrm{mA}$ prepulse $(\mathrm{t}=2.04$, $\mathrm{df}=7, \mathrm{p}<.05)$. In addition, the 1-mA intensity was different from the control with the 5 -sec ISI $(t=2.02, \mathrm{df}=7, \mathrm{p}<.05)$, but there was no significant inhibition with any in-

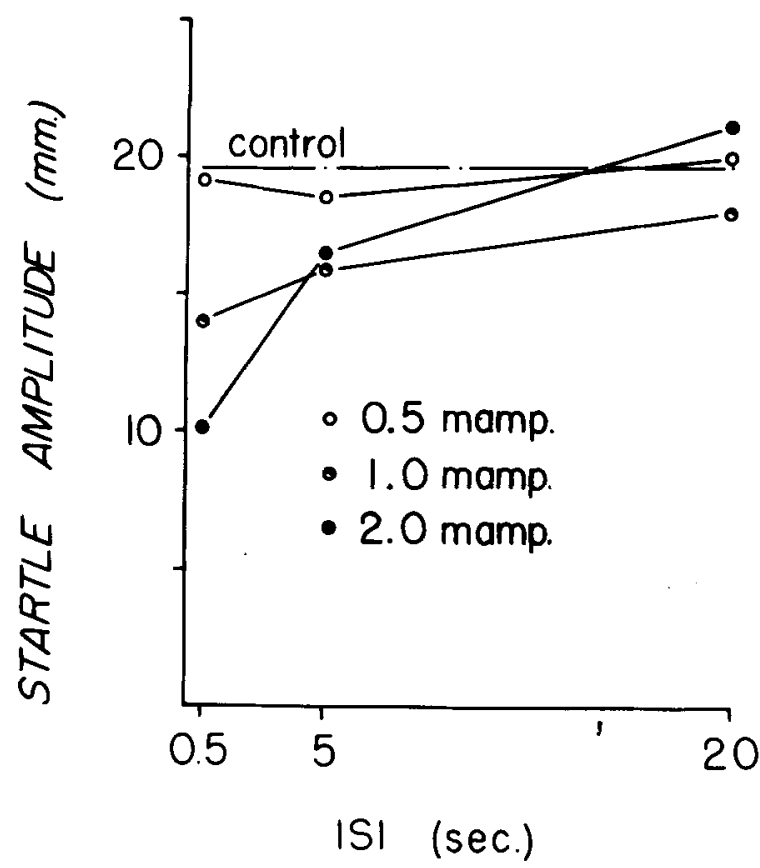

Figure 3. Mean startle amplitudes for three shock prepulses $(.5,1,2 \mathrm{~mA})$ at each ISI $(.5,5,20 \mathrm{sec})$ and control condition. 
tensity at $20 \mathrm{sec}$. The $.5-\mathrm{mA}$ prepulse was not significantly different from control level at any ISI.

The main difference between the results of this study and those of the previous experiment were that the 2-mA prepulse produced significantly greater inhibition than did the 1-mA pulse at the shortest ISI. These results show that increasing the intensity of the shock prepulse increased the magnitude of the inhibitory effect at the shortest ISI, which is consistent with data on sound and light prepulses.

\section{EXPERIMENT 3}

The results of the first experiment suggested that the greatest amount of inhibition is obtained at ISIs shorter than $1 \mathrm{sec}$. This is congruent with data obtained with sound and light prepulses where, indeed, the optimal ISI for the inhibitory effect is around $40 \mathrm{msec}$, with less inhibition at both shorter and longer intervals. It would seem appropriate, then, to investigate the shock prepulse function at shorter intervals. A different technique is required to assess startle behavior with a shock prepulse at very short ISIs because, when the accelerometer is used, residual cage movement from the response to $S_{1}$ makes it difficult to distinguish the response to $S_{2}$. The technique of recording muscle potentials of the flexor and extensor muscles of the rat's fore limb to distinguish sound prepulse responses from startle responses has been used successfully by Hammond, McAdam, and Ison (1972) and was employed in the last experiment of the present series. Inhibition was assessed by changes in EMG latency as well as EMG amplitude, as latency increases are typically associated with inhibition in both neural and behavioral experiments.

\section{Method}

Subjects and Apparatus. The subjects were of the same population as those in the previous experiments, and the apparatus described in Experiment 1 was modified so that EMG responses could be recorded. The recording wires from the subject were plugged into two Grass EEG amplifiers (Model 7P511) which had half-amplitude low-frequency settings of $30 \mathrm{~Hz}$ and halfamplitude high-frequency settings of $3 \mathrm{kHz}$. The gains were set to give good deflection of the oscilloscope (Tektronix Storage, Type 564B) with average EMG amplitudes ranging from 250 to $750 \mathrm{mV}$. Reaction amplitudes were measured in centimeters of deflection on the face of the oscilloscope. The sweep speed was $5 \mathrm{msec} / \mathrm{cm}$ for the $10-\mathrm{msec}$ ISI and $2 \mathrm{msec} / \mathrm{cm}$ for control trials and other ISIs. Responses were photographed for later analysis. The $S_{1}$ and $S_{2}$ durations, the ISI, and the synchronization of the oscilloscope were controlled by two Grass stimulators (Model S8 and SD 5).

Procedure. The rats were anesthetized with $35 \mathrm{mg} / \mathrm{kg}$ sodium pentobarbital, and flexor and extensor muscles of the forelimb were exposed. The electrodes, made from insulated fineguage stranded copper wire, were secured on the surface of each muscle with an additional ground electrode being placed on the extensor. The wires were run under the skin to the back of the neck, where they terminated in a miniature five-pin connector. The incisions were sutured with silk, and the rat was allowed to recover for at least 2 days. (For further details see Hammond, McAdam, \& Ison, 1972.)

Both flexor and extensor responses to the startle stimulus $(120 \mathrm{~dB})$ and the shock $(2.5 \mathrm{~mA}, .1 \mathrm{msec})$ were observed, and the muscle producing the clearest response was selected and used throughout the experimental session. A briefer $(.1-\mathrm{msec})$ but more intense (2.5-mA) shock prepulse was used in this experiment to reduce the shock artifact which otherwise made scoring of short ISI responses difficult. The behavioral response to the shock, however, was comparable to a 1-mA, 1-msec shock used in previous experiments. A series of seven trials were run at each of four ISls-10,40,250, and $1,000 \mathrm{msec}$ - with an additional seven control trials, in a random order. Four subjects were run; however, one subject severed the recording wires after four trials had been run at each interval, and its median data are based on only these trials. Both latency and amplitude of the muscle response was recorded.

\section{Results and Discussion}

The median EMG latencies are shown in Figure 4, the insert showing the data of individual subjects. The function relating EMG latencies to ISI was nonmonotone, increasing from 10 to $40 \mathrm{msec}$ and declining thereafter. The analysis yielded a significant effect of ISI $(F=10.70$, df $=4 / 12, p<.001)$. Further tests showed that there was a significant increase in latency from 10 to $40 \mathrm{msec}(t=2.58$, $\mathrm{df}=3, \mathrm{p}<.05)$ and a significant decrease from 40 to $250 \mathrm{msec}(\mathrm{t}=5.03, \mathrm{df}=3, \mathrm{p}<.01)$ and from 250 to $1,000 \mathrm{msec}(\mathrm{t}=3.40, \mathrm{df}=3, \mathrm{p}<.05)$. There was no difference in latency between $1,000 \mathrm{msec}$ and the control or $10 \mathrm{msec}$ and control, while latencies at $250 \mathrm{msec}$ were significantly longer than the control level $(\mathrm{t}=5.0, \mathrm{df}=3, \mathrm{p}<.01)$.

The median EMG amplitudes are shown in Figure 5 , the inset showing the data of individual subjects. The overall analysis revealed a significant effect of ISI ( $F=7.42$, df $=4 / 12, p<.005$ ). There was a significant decrease in amplitude from

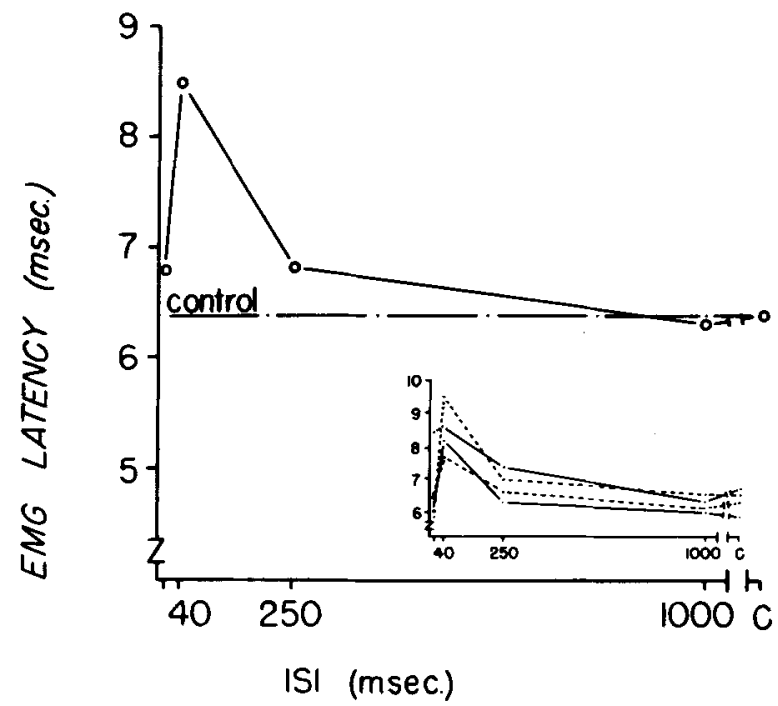

Figure 4. Median EMG latencies at each ISI (10, 40, 250, $1,000 \mathrm{msec}$ ) and control condition, the inset showing data of individual subjects. 


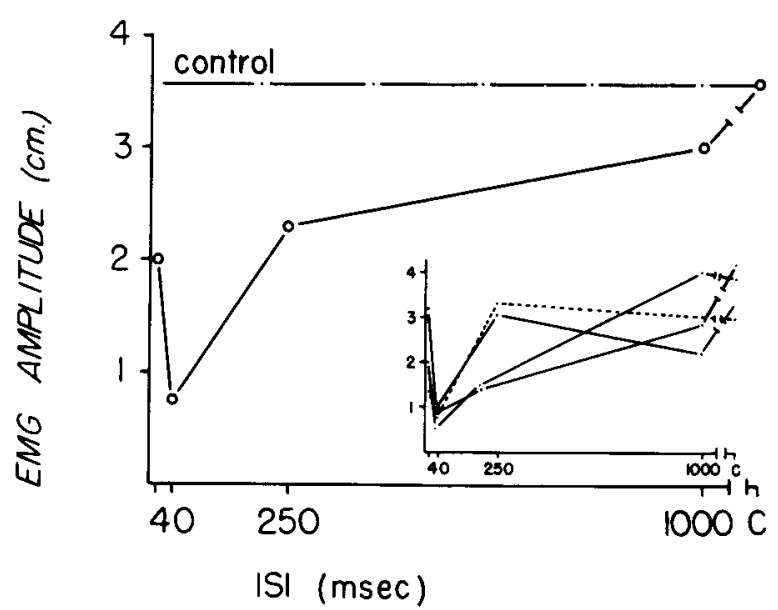

Figure 5. Median EMG amplitudes at each ISI (10, 40, 250, 1,000 msec) and control condition, the inset showing data of individual subjects.

10 to $40 \mathrm{msec}(\mathrm{t}=2.67$, df $=3, \mathrm{p}<.05)$ and an increase from 40 to $250 \mathrm{msec}(\mathrm{t}=3.09, \mathrm{df}=3$, $\mathrm{p}<.05$ ). The amplitudes at 250 and $1,000 \mathrm{msec}$ did not significantly differ from each other, nor did they differ from the control level. The amplitude at $10 \mathrm{msec}$, however, was significantly lower than the control $(\mathrm{t}=2.39$, df $=3, \mathrm{p}<.05)$.

Both the latencies and amplitudes of the EMG responses showed similar nonmonotone functions, with the greatest inhibition occurring at $40 \mathrm{msec}$. This result is consistent with the temporal course of inhibition provided by light and sound prepulses, suggesting that similar processes are involved.

\section{GENERAL DISCUSSION}

Prepulse inhibition of startle behavior appears to be a general phenomenon, occurring with prestimuli in a variety of sensory modalities. The temporal and intensity functions obtained with a brief shock prepulse in the three experiments presented here are nearly identical to those produced by light and sound prepulses as reported in previous research. With all three stimuli, the maximal inhibitory effect occurred when the prepulse preceded the startle stimulus by approximately $40 \mathrm{msec}$, inhibition first increasing to that interval and declining thereafter, and a strong prepulse led to greater and longer lasting inhibition than did a weak one.

These results clarify the earlier finding by Brown et al. (1956) that a 3-5-sec shock presented 1 or $3 \mathrm{sec}$ prior to an auditory startle stimulus resulted in reflex inhibition. These investigators expected that the preshock would produce a drive state which would persist beyond shock termination and yield a facilitation of the startle reflex. Their failure to find shockinduced facilitation was attributed to an effector refractory phase.
In view of the present data, as well as other recent studies, this account seems no longer generally adequate, although refractory effects may have been involved with the intense shocks of long duration used in their study. There does not appear to be a relationship between motor consequence of a preliminary stimulus and its inhibitory effect in this investigation, nor was such a relationship found by Russo, Reiter, and Ison (1975) where the shock response was habituated while its inhibitory effects remained unchanged, or by Hammond, McAdam, and Ison (1972) in comparing the EMG response to an auditory prepulse with its inhibitory effects on the auditory startle reflex. Shocks, lights, sounds, and presumably other punctate stimuli appear to have the same reflex inhibitory effects, depending on their being presented just before the startle stimulus, regardless of their response-eliciting properties.

- Under other testing conditions, these same stimuli may facilitate startle behavior. Pinckney and Ison (Note 2) found an increase in the reflex response on a posttest of 10 startle trials which was preceded by either a rapid series of 27 shocks or a continuous 3-min shock, and Russo et al. (1975) found a sensitization of the auditory startle response produced by a series of 49 regularly spaced brief shocks. Stimuli from other modalities have a similar effect. Ison, Hammond, and Krauter (1973) observed facilitation from a rapid series of light flashes, and Ison and Hammond (1971) and Hoffman and Searle (1965) showed that exposures to moderate-intensity white noise (in the region of 70-75 dB optimally) facilitated startle reactions. Davis (1974) found an additionally facilitatory effect increasing as the subject was exposed to the moderate white noise over a duration of $30 \mathrm{~min}$.

It would appear that the same stimuli, visual, auditory, or tactile which produce inhibition under some temporal conditions, produce facilitation under other conditions. The important variable may not be the modality of the preliminary stimulus or whether it elicits a response, but that it be presented in an appropriate relationship with the reflex. The effect of the stimulus measured within about $40 \mathrm{msec}$ or so of its onset is inhibitory, whereas its effect measured after it has been on for some longer period of time or has been successively repeated at intervals of a few seconds apart is facilitatory.

\section{REFERENCE NOTES}

1. Ash, B. L., Parisi, T., \& Ison, J. R. Modification of acoustic and tactile reflexes in the rat by visual stimulation. Manuscript submitted for publication, 1976.

2. Pinckney, L. A., \& Ison, J. R. Startle reflex behavior and exposure to electric shock. Paper presented at the meeting of the Midwestern Psychological Association, Cincinnati, Ohio, May 1970 . 


\section{REFERENCES}

Brown, J. S., Meryman, J. W., \& Marzocco, F. N. Soundinduced startle response as a function of time since shock. Journal of Comparative and Physiological Psychology, 1956, 49. $190 \cdot 194$.

Buckland, G., Buckland, J., Jamieson, C., \& Ison, J. R. Inhibition of startle response to acoustic stimulation produced by visual pre-stimulation. Journal of Comparative and Physiological Psychology, 1969, 67, 493-496.

DAvis, M. Sensitization of the rat startle response by noise. Journal of Comparative and Physiological Psychology, 1974, 87, 571-581.

Graham, F. K. The more or less startling effects of weak prestimulation. Psychophysiology, 1975, 12, 238-248.

Hammond, G. R., MCADAM, D. W., \& Ison, J. R. Effects of prestimulation on the electromyographic response associated with the acoustic startle reaction in rats. Physiology and Behavior, 1972, 8, 535-537.

Hoffman. H. S., \& Searle, J. L. Acoustic variables in the modification of the startle reaction in the rat. Joumal of Comparative and Physiological Psychology, 1965, 60, 53-58.

Hoffman, H. S., \& Wible, B. L. Role of weak signals in acoustic startle. Journal of the Acoustical Society of America, 1970, 47, 489-497.

Ison, J. R., \& Hammond, G. R. Modification of the startle reflex in the rat by changes in the auditory and visual environments. Journal of Comparative and Physiological Psychology, 1971, 75, 435-452.
Ison, J. R., Hammond, G. R., \& Krauter, E. E. Effects of experience on stimulus produced reflex inhibition in the rat. Journal of Comparative and Physiological Psychology, 1973, 83, 324-336.

Ison, J. R., \& LeONARD, D. W. Effects of auditory stimuli on the amplitude of the nictitating membrane reflex of the rabbit (Oryctolagus cuniculus). Journal of Comparative and Physiological Psychology, 1971, 75, 157-164.

KraUter, E. E., LEONARD, D. W., \& Ison, J. R. Inhibition of the human eyeblink by a brief acoustic stimulus. Journal of Comparative and Physiological Psychology, 1973, 84, 246-251.

Pinckney, L. A. Inhibition of the startle reflex in the rat by prior electrical stimulation. Unpublished $\mathrm{PhD}$ dissertation, University of Rochester, 1970.

Russo, J. M., Reiter, L. A., \& Ison, J. R. Repetitive exposure does not attenuate the sensory impact of the habituated stimulus. Journal of Comparative and Physiological Psychology, 1975, 88, 665-669.

Stitt, C. L., Hoffman, H. S., Marsh, R. R., \& Schwartz, G. M. Modification of the pigeon's visual startle reaction by the sensory environment. Journal of Comparative and Physiological Psychology, 1976, in "press.

(Received for publication March 15, 1976; revision received August 28, 1976.) 